\title{
Up- and downshoot in adduction after monocular patching in normal volunteers
}

\author{
A. LIESCH and H.J. SIMONSZ*
}

Department for Strabismus \& Neuro-ophthalmology, Eye Clinic, Kantonsspital, Sankt Gallen, Switzerland and the Netherlands Ophthalmic Research Institute, Amsterdam, The Netherlands

\begin{abstract}
Upshoot-in-adduction and downshoot-in-adduction are non-paretic motility disorders that usually accompany a horizontal squint in children, together with V-or A-pattern motility. Upshoot-in-adduction may sometime mimic a superior oblique palsy. The authors have found that even in healthy volunteers these motility disorders can be found and made manifest by patching. One eye of complaint-free volunteers with full stereopsis was patched for three days. Then the eye movements of the patched eye were recorded with the search coil technique, first before taking the patch off and secondly after putting the patch on the other eye. The latter registration served as reference for the first registration. It was found that 11 out of 18 volunteers had developed an upshoot-in-adduction of the patched eye. In five cases no directional change was found whereas two cases had developed a downshoot-in-adduction. It seems that up- and downshoot-in-adduction are latent motility disorders that become manifest after disruption of fusion. In addition, the authors found undershooting saccades and postsaccadic drift of the patched eyes.
\end{abstract}

Key words: strabismus; eye movements; eye motility disorders; saccades; binocular vision

\section{INTRODUCTION}

The cause of up- and downshoot-in-adduction is a controversial issue. Some authors consider most cases of upshoot-in-adduction as trochlear palsies ${ }^{1-4}$. When there is no obvious cause for a palsy like a trauma or a neurological disorder, the trochlear palsy is considered congenital. Some think that a palsy of the contralateral superior rectus is a contributing factor ${ }^{3,5}$. In some cases of upshoot-in-adduction, the vertical

*Correspondence to: Dr. H.J. Simonsz, section Orthoptics \& Neuro-ophthalmology, Department of Ophthalmology, University Hospital Dijkzigt, Dr. Molewaterplein 40, NL 3015 GD Rotterdam, The Netherlands. deviation (VD) increases in adduction-upgaze instead of adduction-downgaze, contrary to the general principle that the angle of squint caused by an eye muscle palsy increases when the patient attempts to look into the field of action of the muscle. This discrepancy was discussed in detail by Bielschowsky ${ }^{6}$ who, among other things, considered an increase of the VD in adduction-up as incompatible with a superior oblique palsy, although he had observed longstanding cases of acquired superior oblique muscle palsy that had less or no difference between the VD in adduction-up and the VD in adduction-downgaze. He considered cases with an increase of the VD in adduction-up as a primary 
overaction of the inferior oblique muscle, but he emphasized that, although the name of the disorder seemed to assign the defect to the inferior oblique muscle, he in fact did not know for sure which structure was involved. Since Bielschowsky, primary overaction of the inferior oblique muscle is described by many as a separate entity ${ }^{7}$, whereas others try to explain the motility disorder by invoking complicated anatomical or innervational abnormalities ${ }^{8-10}$. It is remarkable that in all these explanations the authors have tried to assign the cause of the motility disorder to a single muscle or single other structure. The problem is compounded by the fact that the Bielschowsky head-tilt test (VD changing on head-tilt to either shoulder), which is classically considered as indicative of a superior oblique muscle palsy ${ }^{11}$, can be positive in cases of upshoot-in-adduction that have an increase of the VD in adduction-upgaze.

Viirre et al..$^{12}$ found in normal monkeys that disruption of fusion by patching one eye for a week made latent aberrations of conjugate horizontal eye movement become manifest: They found slightly skewed horizontal eye movements of the occluded eye after patching this eye for a week, and concluded that the direction of horizontal eye movement of the two eyes relative to each other is calibrated by fusion.

We have repeated the experiments of Viirre et $a l$ in 18 complaint-free, non-strabismic human volunteers with normal binocular vision. Similar to the findings of Viirre et al. in monkeys, we found up- and downshoot-in-adduction of the patched eye. In addition, we found saccadic undershoot and postsaccadic drift. These changes disappeared rapidly after reinstating fusion.

\section{METHODS}

Eighteen human volunteers were recruited among relatives and colleagues. They were asymptomatic and non-strabismic, with normal binocular vision, having a random-dot stereopsis disparity threshold of 60 seconds of arc or better. All were adults, with three exceptions who were 11, 14 and 16 years old. All gave oral informed consent.

One eye of each volunteer was patched for three days. The patch was a self-adhesive occlusive plaster normally used in the treatment of amblyopia (Elastopad, Beiersdorf AG, Hamburg). After three days the volunteer returned to the department and the eye movements of the eye that had been patched were recorded while the other eye made $40^{\circ}$ horizontal target saccades. The search-coil technique for recording eye movements was used ${ }^{13,14}$ (Skalar, Delft, Holland). During the period of registration (20s) the volunteer looked to and fro between two points, fixed on a screen in front of the subject, with a $20^{\circ}$ gaze angle left and right from gazeahead. The distance between the screen and the volunteer's head was $2.5 \mathrm{~m}$.

For the first registration, we put the search coil on the eye behind the patch in the dark. We dazzled the volunteer's eye with a small torch so the eye could not see anything but we could still see the eye. Then the patch was put back on the eye and roomlights were turned on. Horizontal eye movements of the eye that had been and still was patched were recorded while the other eye made $40^{\circ}$ horizontal target saccades.

Then we took the patch off, thus allowing fusion for a few minutes. In this period some of our volunteers had diplopia which disappeared quickly, after 15 minutes at most. The patch was put on the other eye. We now made exactly the same recording of eye movement as before, with 
the difference that now the previously patched eye made the $40^{\circ}$ horizontal target saccades. The second registration served as reference for the first registration. We did not record eye movements before patching for three days, because that would possibly have discouraged the volunteers from coming back.

For analysis of the recordings we used the SEARCH programme. It is an extended version of the SELSPOT programme, which was developed to record head and eye movements using the Selspot hardware. The SELSPOT programme was originally developed on a PDP11/ 23 computer in 1985. In 1990 it was transferred to the IBM PC, whereby new functions and Microsoft EXCEL compatible file output were added. SEARCH is a modified version of SELSPOT for use with the SKALAR Model 3000 Eye Position Meter.

As it was not possible in our experiments to calibrate the search coil system by putting the search coils in a known absolute position, we derived absolute eye position empirically by having the subject (with one eye covered) fixate a target in the middle of the screen and subtracting the difference between previously chosen reference position and the found eye position from the previously recorded data of this eye. Two versions of the SEARCH programme were implemented: Eye movements were presented as two dimensional graphs with horizontal and vertical eye position, and as two registrations representing horizontal and vertical eye position as a function of elapsed time.

Due to distortions of the magnetic fields, the true horizontal eye movements of left eyes are represented in the figures as being somewhat oblique. However, this is of little importance in the present study because we were only interested in changes occurring after disruption of fusion, whereby the second registration served as refer- ence for the first registration. The magnetic field was hardly tilted for the right eye.

\section{RESULTS}

Eleven out of 18 volunteers developed an upshoot-in-adduction. In the six most marked cases, the angle between the trajectories of the saccades before and after putting the patch on the other eye was between $3^{\circ}$ and $5^{\circ}$. In the other five cases, the angle was $1^{\circ}$ to $2^{\circ}$. Translated into orthoptic terms, a $5^{\circ}$ angle between the trajectories of the saccades before and after putting the patch on the other eye would mean that the vertical angle of squint would change by $3.5^{\circ}$ if a patient looked from $20^{\circ}$ left gaze to $20^{\circ}$ right gaze. Five cases showed no directional change of the occluded eye and two cases showed a downshoot-in-adduction. We also found undershooting saccades and postsaccadic drift.

In Figs. 1-9 movements of the eye that had been patched for three days are depicted. Each figure contains two registrations of eye movements during two periods of 20 s, during which the volunteer made $40^{\circ}$ horizontal target saccades. The abscissa represents horizontal eye position and the ordinate represents vertical eye position. One division on either scale equals $5^{\circ}$ of eye position. In Figs. 1-5 the left eye was patched for three days. In Figs. 6-9 the right eve was patched for three days. In all figures the series $\mathrm{A}$ of saccades represent the saccades before taking the patch off, and the series B represent the saccades after putting the patch onto the other eye.

When there was no vertical angle of squint after three days of occlusion, as in Fig. 2, the two series of saccades overlap and cannot be distinguished in these black \& white figures. In some cases, only a vertical angle of squint had developed after three days of patching. This vertical 


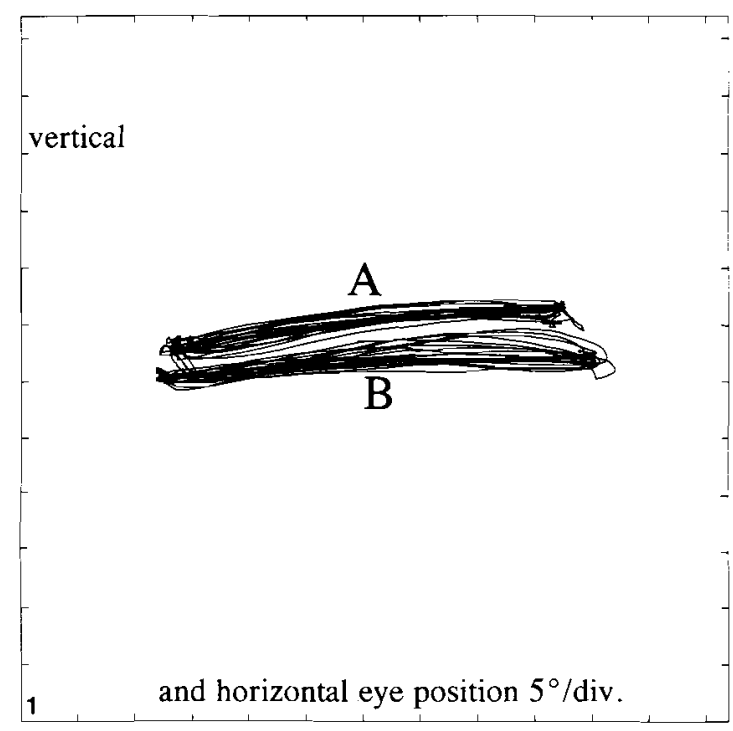

Fig. I. (left eye). In Figs. 1-9 two registrations (A and B) are depicted of eye movements of the same eye during two periods of $20 \mathrm{~s}$, during which the volunteers made $40^{\circ}$ horizontal saccades. In Figs. 1-9 the first series (A) of saccades represent the saccades of the patched eye before we took the patch off, and the second series of saccades $(B)$ represent the horizontal saccades of the same eye after we put the patch onto the other eye. Between these two registrations was a period of about 15 minutes during which the volunteer could see with both eyes. At the beginning of this period some patients had diplopia but this disappeared within 15 minutes. Because the volunteer's head was fixed and there was no change in the magnetic field, we did not make a new calibration for the second registration. Due to distortions of the magnetic fields, the horizontal eye movements of the left eye are represented in Figs. $1-5$ as being somewhat oblique. However, this is of little importance in the present study because we were only interested in changes occurring after disruption of fusion, whereby the second registration (B) served as reference for the first registration (A). The abscissa represents horizontal eye position and the ordinate represents vertical eye position. One division on either scale equals $5^{\circ}$ of eye position. Volunteer 4 had developed an upshoot-in-adduction (estimated average angle between registrations $\mathrm{A}$ and $\mathrm{B}$ was about $4.5^{\circ}$ ), combined with a small vertical angle of squint and undershooting saccades, mainly nasally directed. After we took the patch off, this volunteer had diplopia for some minutes.

angle of squint was $3.5^{\circ}$ in the most marked case (Fig. 6). Others only developed an upshoot-in-

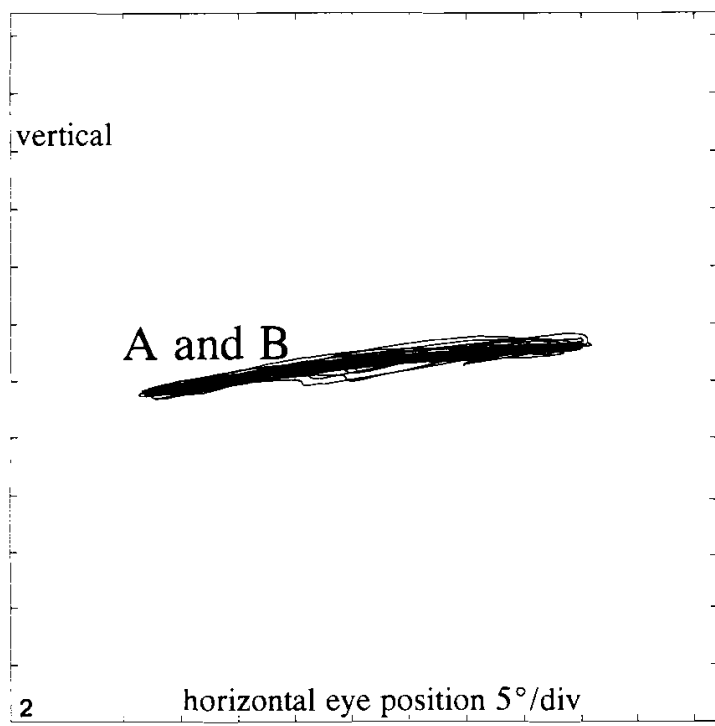

Fig. 2. (left eye, volunteer 1). When there was no change in the horizontal eye movements after three days of occlusion, as in this case, the two series of saccades overlap and cannot be distinguished.

adduction (Figs. 3, 4 and 8): a vertical angle of squint was only present when the eye that had been patched for three days adducted. In some cases the vertical angle of squint was combined with an upshoot-in-adduction (Figs. 1, 5 and 7). Some had also developed undershooting saccades. Two cases developed a downshoot-inadduction (Fig. 9).

In Figs. 10 and 11 eye movement data are presented as two curves of data presented as horizontal and vertical eye position as a function of elapsed time. Horizontal eye position (upper registration) and vertical eye position (lower registration) are represented by the ordinate, bar equals $5^{\circ}$. Up represents rightward eye movement in the top trace, up represents upward eye movement in the bottom trace. Abscissa represents time, one division equals $1 \mathrm{~s}$. We found postsaccadic drift of the patched eye, in this case directed nasally. Only two cases had temporally 
TABLE 1. Below detailed information about the extent of skewedness of saccades, vertical angle of squint and undershoot are given. A: number of volunteer. B: the eye that had been patched for three days was first recorded while the volunteer made saccades with the other eye and was then recorded while the volunteer made saccades with this eye (as a reference); the difference in direction between the two is the skewedness of the horizontal saccades of the eye behind the patch. Positive values indicate an upshoot-in-adduction, negative values a downshoot-in-adduction. C: vertical angle of squint in $20^{\circ}$ of adduction. Positive values indicate a hypertropia of the patched eye. D: the same in $20^{\circ}$ of abduction. E: difference between $\mathrm{C}$ and $\mathrm{D}$, as a measure of incomitance of the hypertropia. F: undershoot of saccades, when present, in degrees. G: direction of postsaccadic drift, when present, at the end of a saccade into adduction. $\mathrm{H}$ : the same for saccades into abduction.

\begin{tabular}{|c|c|c|c|c|c|c|c|}
\hline$A$ & $B$ & $C$ & $D$ & $E$ & $F$ & $G$ & $H$ \\
\hline 1 & 0 & 0 & 0 & - & - & - & - \\
\hline 2 & 3 & 1.2 & -0.9 & 2.1 & 3.5 & - & - \\
\hline 3 & 1 & 0.8 & 0.1 & 0.7 & - & nas & - \\
\hline 4 & 3 & 4.8 & 2.7 & 2.1 & 3.5 & nas & nas \\
\hline 5 & 0 & 2 & 2 & 0 & - & nas & nas \\
\hline 6 & 1 & 0.7 & 0 & 0.7 & - & nas & nas \\
\hline 7 & 2 & 1.4 & 0 & 1.4 & - & nas & - \\
\hline 8 & 4.5 & 4.7 & 1.6 & 3.1 & - & nas & - \\
\hline 9 & -1 & 1.2 & 1.9 & -0.7 & - & - & - \\
\hline 10 & 4.8 & 3.4 & 0 & 3.4 & - & - & - \\
\hline 11 & 5 & 3.5 & 0 & 3.5 & 1.75 & - & - \\
\hline 12 & 0 & 0 & 0 & 0 & - & nas & nas \\
\hline 13 & -4 & 0 & 2.8 & -2.8 & - & nas & temp \\
\hline 14 & 2 & 1.4 & 0 & 1.4 & - & temp & temp \\
\hline 15 & 0 & 2.7 & 2.7 & 0 & - & - & - \\
\hline 16 & 1 & 0.7 & 0 & 0.7 & - & nas & - \\
\hline 17 & 3 & -2.3 & -4.4 & 2.1 & 1.75 & nas & - \\
\hline 18 & 0 & 0 & 0 & 0 & - & - & - \\
\hline
\end{tabular}

directed postsaccadic drift. The drift occurred more often in adduction as compared to abduction. Quantitative detailed data are given in Table 1.

\section{DISCUSSION}

In our 18 volunteers we found three different changes of the horizontal eye movements after three days of patching one eye.

First, eleven cases had developed an upshootin-adduction, five cases showed no directional change and only two cases had developed a downshoot-in-adduction. In seven cases the angle between the first and the second registration was between 3 and $5^{\circ}$ (as said before, a $5^{\circ}$ angle between the trajectories of the saccades of both eyes would mean that the vertical angle of squint would change by $3.5^{\circ}$ if a patient looked from $20^{\circ}$ left gaze to $20^{\circ}$ right gaze). In the other six cases the angle between the first and the second registration was between 1 and $2^{\circ}$. In addition, we found vertical angles of squint (up to $3.5^{\circ}$ ).

Secondly, 11 of the volunteers had developed a postsaccadic drift, which means: the movement of the patched eye did not immediately stop after a saccade but slowly went on for a short period. It was most often directed nasally. Postsaccadic drift is the result of a mismatch between the saccadic pulse and the saccadic step of innervation and it seems logical that vision is needed for calibration of the relation between the saccadic step and the saccadic pulse.

Thirdly, in some cases we found undershooting saccades. In some cases the saccades of the patched eye fell significantly short of $40^{\circ}$. 


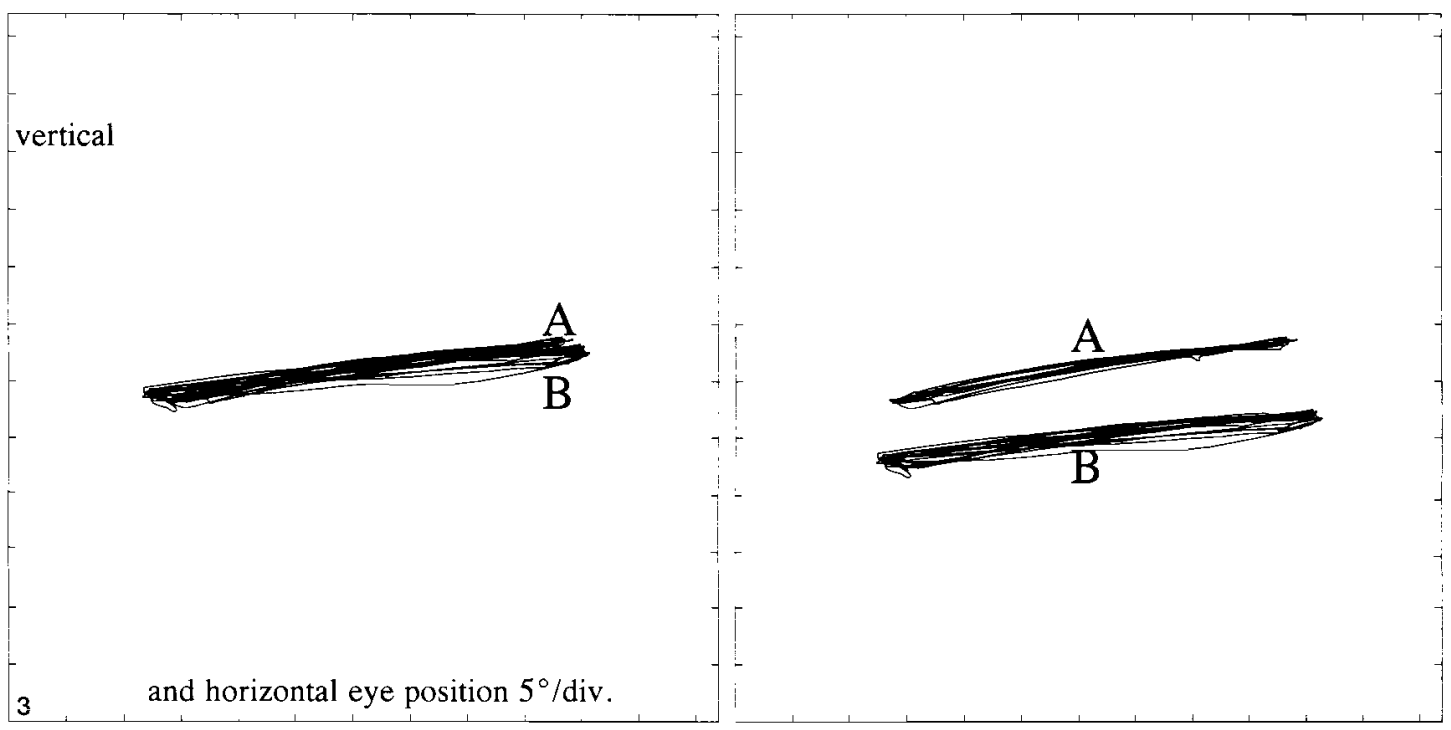

Fig. 3. (left eye, volunteer 2). Left: This volunteer had developed an upshoot-in-adduction (average estimated angle between registrations $\mathrm{A}$ and $\mathrm{B}$ was about $3^{\circ}$ ) and undershooting saccades. Because the two registrations overlap, they can hardly be distinguished. Right: Here are the same registrations as on the left panel, but to make the distinction easier, registration $\mathrm{B}$ has been moved downward by $5^{\circ}$.

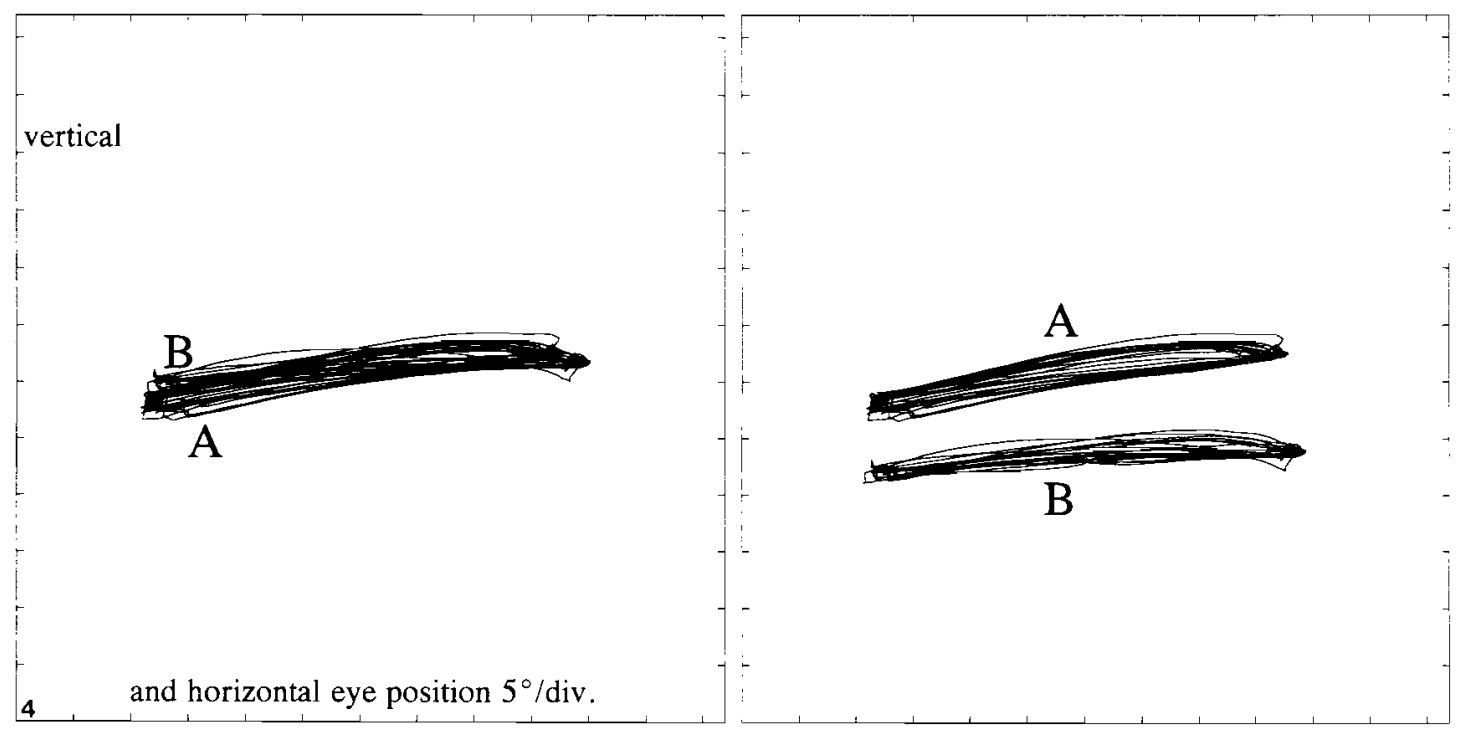

Fig. 4. (left eye, volunteer 10). This volunteer had developed an upshoot-in-adduction (average estimated angle between registrations $\mathrm{A}$ and $\mathrm{B}$ was about $5^{\circ}$ ). He too had diplopia for some minutes after we took the patch off. On the right are the same registrations but registration $B$ has been moved downwards by $5^{\circ}$ to make the distinction easier. 


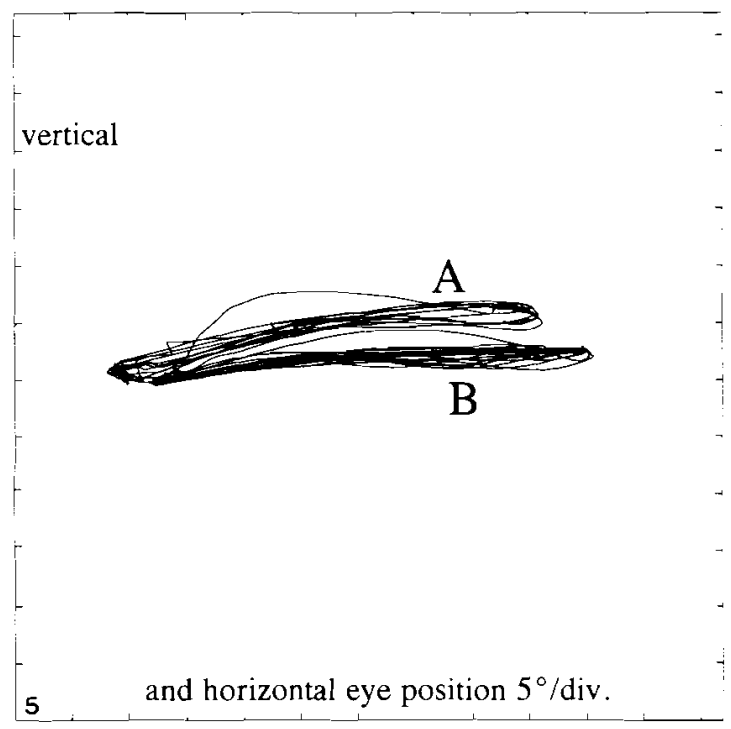

Fig. 5. (left eye, volunteer 8). This volunteer had developed an upshoot-in-adduction (estimated average angle between $\mathrm{A}$ and $\mathrm{B}$ was about $4.5^{\circ}$ ) and a vertical angle of squint.

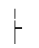

'vertical

-

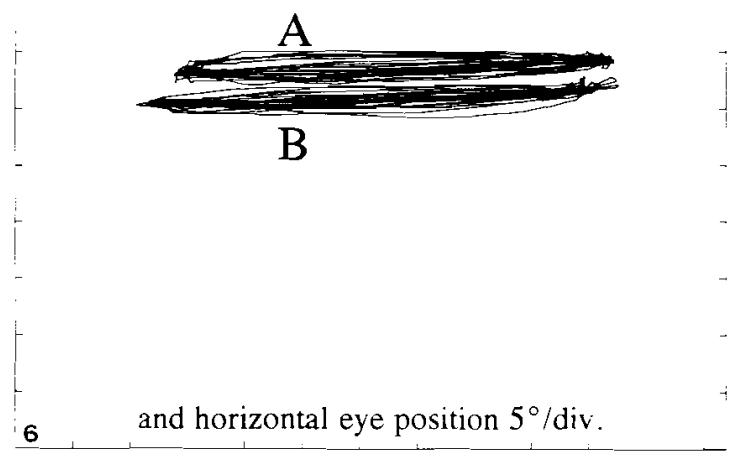

Fig. 6. (right eye, volunteer 15). This volunteer had developed a constant vertical angle of squint (about $3.5^{\circ}$ ). This was the largest vertical angle of squint we found. In Figs. 6-9 the right eye had been patched for three days and was recorded before taking the patch off and after putting it onto the other eye. Left is nasal, right is temporal. vertical

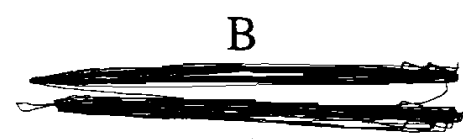

A

7

and horizontal eye position $5 \%$ div

Fig. 7. (right eye, volunteer 17). Upshoot-in-adduction (estimated average angle between registrations of $\mathrm{A}$ and $\mathrm{B}$ was about $3^{\circ}$ ), combined with a constant vertical angle of squint and undershooting saccades in the nasal direction.

In general, these three changes of horizontal eye movements that occurred after patching one eye for three days parallel the findings of Viirre et al. in monkeys. However, the five monkeys studied by them all developed a downshoot-inadduction, whereas most of our subjects developed an upshoot-in-adduction. It is interesting to note that not only in our study group but also among children with a horizontal squint, upshoot-in-adduction is far more common than downshoot-in-adduction. In all five monkeys the length of the saccades of the patched eye changed, most often saccades became shorter. We also found undershooting saccades but only in four cases. The postsaccadic drift of the patched eye was directed temporally in the monkeys of Viirre et al., whereas it was directed nasally in our volunteers. We found, translated into orthoptic terms, a maximum difference in vertical angle of squint, measured in $20^{\circ}$ left 


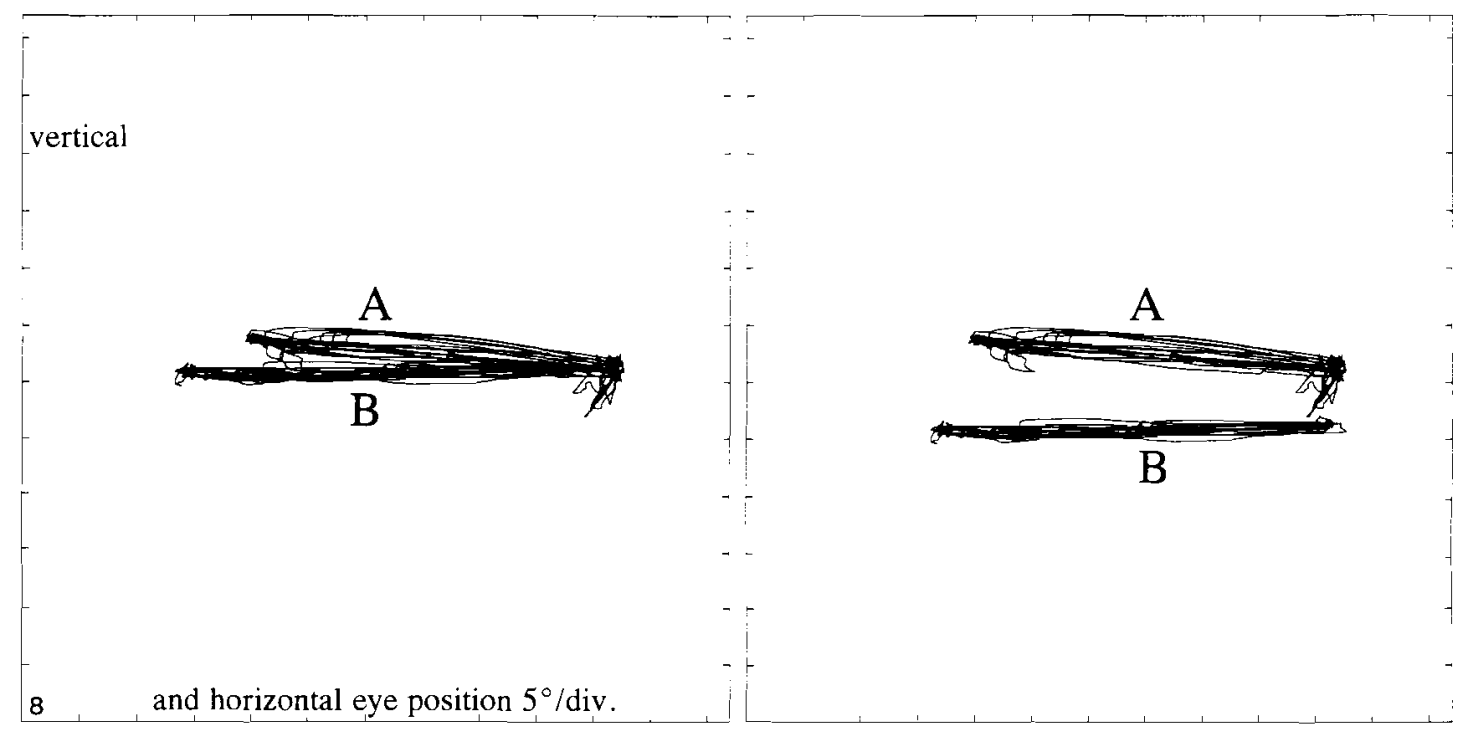

Fig. 8. (right eye, volunteer 11). Left: Upshoot-in-adduction (estimated average angle between registrations A and B was about $5^{\circ}$ ) and undershooting of the nasally directed saccades. This volunteer had diplopia. Right: Same registrations as on the left panel, but in the right panel, registration $B$ is moved $5^{\circ}$ downward, to make the distinction easier.

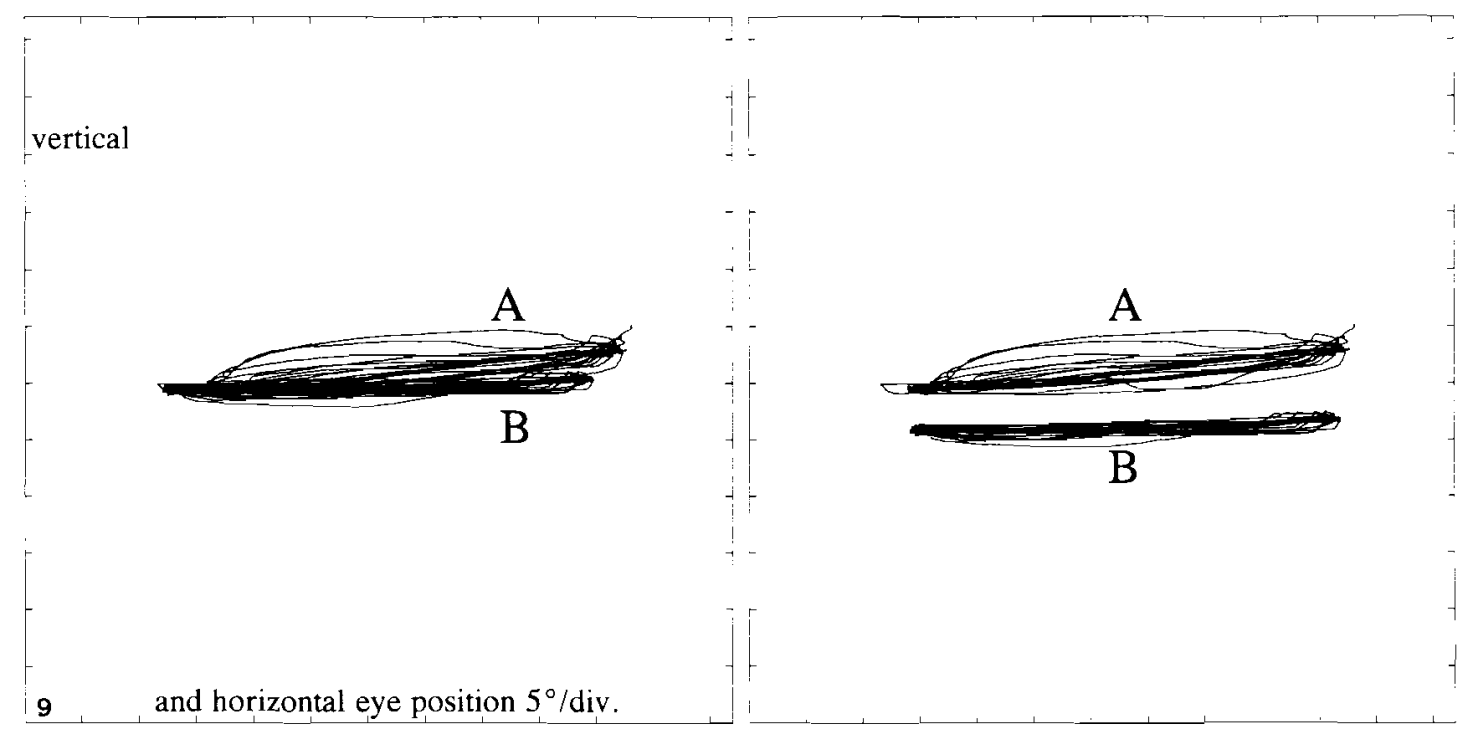

Fig. 9. (right eye, volunteer 13). This volunteer developed a downshoot-in-adduction (estimated average angle between registrations between $\mathrm{A}$ and $\mathrm{B}$ was about $4^{\circ}$ ). 


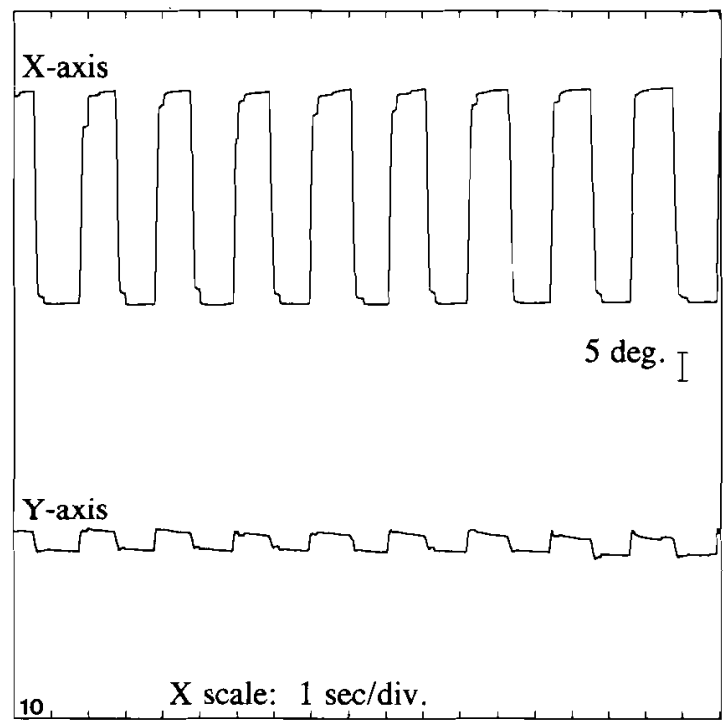

Fig. 10. (left eye, volunteer 3). In Figs. 10 and 11 movement data are presented as two registrations representing horizontal and vertical position as a function of elapsed time. Horizontal eye position (upper registration) and vertical eye position (lower registration) are represented by the ordinate, bar equals $5^{\circ}$. Upward is rightward eye movement in the top trace and upward eye movement in the bottom trace. Abscissa represents time, one division equals $1 \mathrm{~s}$. Here the postsaccadic drift was directed nasally, and occurred in adduction.

gaze and $20^{\circ}$ right gaze, of $3.5^{\circ}$. This may seem little, but it is not: If such an incomitance of the vertical angle of squint develops after only three days of occlusion, large upshoots-in-adduction as encountered clinically may well develop over periods of months in young children. This conforms to clinical observations that up- and downshoot-in-adduction usually develop some months after the onset of a horizontal squint. Large upshoots-in-adduction do not develop in adults when fusion is disrupted, for instance, by a cataract. It is possible that the anatomical, physiological and innervational conditions become less plastic with age, hence permitting less change of the direction of horizontal saccades ${ }^{15}$.

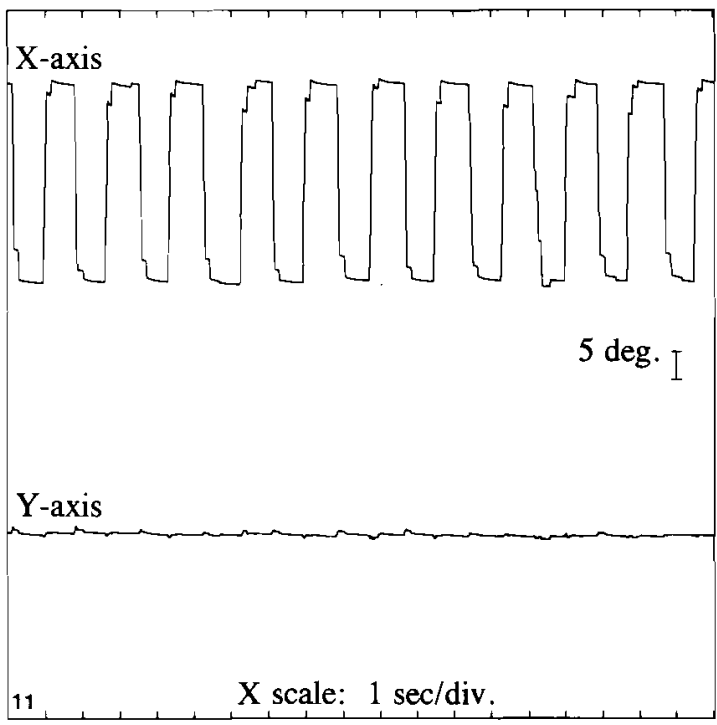

Fig. 11. (right eye, volunteer 5). Here the postsaccadic drift was directed nasally, and occurred in abduction as well as in adduction.

What is the reason for the latent motility disorder? Considering the variability of the anatomy, the physiology and the innervation of the eye muscles ${ }^{16,17}$ it seems an unlikely event that both eyes would move exactly in the same direction just by chance. As most normal people have almost perfectly conjugate horizontal eye movements, it seems that some fine-tuning mechanism must be present for this to happen. The study of Viirre et al. and this study show that the fine-tuning mechanism employs binocular vision. Without binocular vision, the eye movements of the patched eye become skewed. To what extent they will become skewed is determined by many random variables like the anatomy of the eye, muscles and orbit and the innervational wiring in the brainstem.

The resulting motility disorder cannot be described adequately by the term 'overacting inferior oblique muscle'. We propose to stop using 

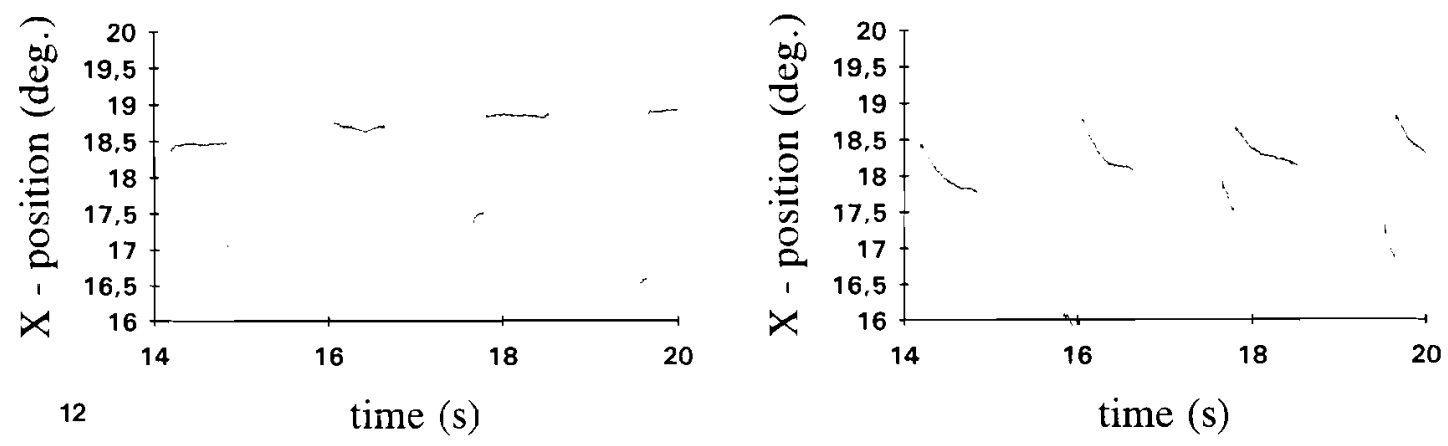

Fig. 12. (left and right eye, volunteer 5). The right panel of this figure is an enlarged part of the upper right part of Fig. 11. It is the movement of the right eye. The left panel represents the corresponding movement of the left eye; the volunteer had a search-coil on both eyes. Note the postsaccadic drift of the patched eye and the lack of such movement of the seeing eye.

such terms that assign a non-paretic motility defect to a single anatomical structure. The terms 'up- and downshoot-in-adduction' or 'strabismus surso- and deorsoadductorius' are adequate descriptive terms, they describe the motility disorder very well and are, hence, preferable.

Weingarten and Guyton ${ }^{18}$ presented evidence supporting our model and extended it to include torsion (anatomical excyclotorsion is found in most cases of upshoot-in-adduction with $\mathrm{V}$ patterns and anatomical incyclotorsion is found in most cases of downshoot-in-adduction with A-pattern, and the three phenomena are mechanically related). They induced incyclovergence by having volunteers look at slanted vertical stripes for half an hour and afterwards recorded vertical and horizontal eye movements. They found that in this way, they could induce downshoot-in-adduction and even an A-pattern motility. These authors seek the reason for the occurrence of the latent motility disorder primarily in a latent anatomical cyclotropia, whereas we would prefer to translate this into a more general complex of latent upshoot-inadduction, V-pattern and anatomical excyclotropia, for example.
In addition to the course of events explained above, namely a latent motility disorder becoming manifest after the disruption of fusion, we think that in some cases the course of events may be the reverse. That is, we think that in some cases a latent upshoot-in-adduction can become so strong that it overcomes fusion. The resulting motility can then even mimic a trochlear palsy. We have previously found ${ }^{19,20}$ in length-tension recordings of oblique eye muscles in patients operated under local eye-drop anaesthesia, that some patients with a motility typical of a superior oblique palsy (VD increasing in adduction, in downgaze and on head-tilt, V-pattern and excyclotropia) had vividly contracting superior oblique muscles. Their superior oblique muscles shortened $8 \mathrm{~mm}$ which is incompatible with a superior oblique palsy of any magnitude. The difference in VD on right and left head-tilt (Bielschowsky's head-tilt test) was $13^{\circ}$ in one patient!

Following the ideas of $\mathrm{H}$. Kaufmann and G.H. Kolling, we think that these patients, instead of having a congenital superior oblique palsy, had a large latent motility disorder that overcame fusion. In this model, the course of events is the reverse: the latent motility disorder is too strong to handle for the mechanism that 
calibrated by means of fusion. This non-paretic motility disorder we suggest to call 'primary' upshoot-in-adduction or 'primary' strabismus sursoadductorius, to be distinguished from 'secondary' upshoot-in-adduction resulting from disruption of fusion.

As mentioned previously, the Bielschowsky head-tilt test can be positive in primary upshootin-adduction. How is that possible? We have previously sought to explain very large amplitudes of change of the VD in the Bielschowsky head-tilt test by trying to correlate them to the amplitude of the ocular counterrolling reflex that is classically considered as the driver of the Bielschowsky head-tilt test ${ }^{11}$. We could only substantiate this relation in recent-onset palsies; in long-standing cases the relation was erratic ${ }^{21}$. (As a matter of fact, some of the long-standing cases we would now no longer diagnose as congenital superior oblique palsies, but as primary strabismus sursoadductorius.) Robinson ${ }^{22}$ showed in a computer-model study that secondary overaction of the vertical recti had to be invoked to explain very large changes of the VD in the Bielschowsky head-tilt test. This means that the gain of the otolith-reflex input to the vertical recti can be turned up or down. Turning the gain of the otolith-reflex input to the vertical recti up is certainly advantageous to the patient with a small VD: It allows the patient to have single binocular vision with the least possible head tilt $^{23}$ (original idea from V. Herzau ${ }^{24}$ ).

\section{REFERENCES}

1. Wieser D. Zur Klinik und Therapie der kongenitalen Trochlearisparese. Klin Mbl Augenheilk 1982; 180:647-470.

2. Crone RA. Diplopia. Amsterdam: Excerpta Medica, 1973; 237-266.

3. Parks MM. The overacting factor oblique muscle. Am J Ophthalmol 1974; 77:787-797.

4. Parks MM. Ocular motility and strabismus. New York: Harper and Row, 1975; $143-148$.

5. Anderson JR. Sidelights on the inferior oblique muscle. Br J Ophthalmol 1948; 22:653-668.

6. Bielschowsky A. Die Motilitätstörungen der Augen. In: Handbuch der gesamten Augenheilkunde, 2nd edn. Graefe, Saemisch (editors). Berlin: Springer, 1932; Vol 8, Part 1, Chapter XI.

7. Lang J. Strabismus, 3rd edn. Berne: Huber, 1986.

8. Guibor GP. Synkinetic overaction of the inferior oblique muscle. Am J Ophthalmol 1949; 32:221-229.

9. Villa-Seca A. Surgical classification of squints with a vertical deviation. Br J Ophthalmol 1955; 39:129-150.

10. Kaufmann H. Mechanik pathologischer Augenbewegungen. In: Strabismus. Kaufmann H (editor). Stuttgart: Enke Verlag, 1986; 117-118.

11. Nagel A. Ueber das Vorkommen von wahren Rollungen des Auges um die Gesichtslinie. Alb v Graefes Arch Ophthalmol $1871 ; 17: 237-264$.

12. Viirre $E$, Cadera $W$, Vilis $T$. The pattern of changes produced in the saccadic system and vestibulo-ocular reflex by visually patching one eye. J Neurophysiol 1987; 57:92-103.

13. Robinson DA. A Method of measuring eye movement using a scleral search coil in a magnetic field. IEEE Transactions on Biomedical Engineering 1963; 10:137-145.

14. Collewijn H, van der Merk F, Jansen TC. Precise recording of human eye movements. Vision Res 1975; 15:447-450.

15. Lemij HG, Collewijn $\mathrm{H}$. Nonconjugate adaption of human saccades to anisometric spectacles: Meridian-specificity. Vision Res 1992; 32:453-464.

16. Fink H. Surgery of the Vertical Muscles of the Eye, 2nd edn. Springfield: CC Thomas, 1962.

17. Saunders RA, Croley TL, Croley MR, Holgate RC. The relationship of rectus muscles to the globe: a study with coronal CT scanning. J Pediat Ophthalmol \& Strabismus 1986; 23:176-182.

18. Weingarten PE, Guyton DL. Etiology of primary oblique muscle overaction/underaction. Invest Ophthalmol 1992; 33(ARVO Suppl):871.

19. Simonsz HJ, Reckert I, Török B. Längen-Spannungs-Messungen von Obliqui bei Schieloperationen zur Differenzierung von Trochlearis-Paresen und Strabismus sursoadductorius. Klin Mbl Augenheilk 1992; 200:414-417.

20. Simonsz HJ. Length-tension properties of isolated, human, oblique eye muscles at different levels of natural innervation. Invest Ophthalmol 1992; 32(ARVO Suppl):821. 
21. Simonsz HJ, Crone RA, van der Meer J, Merckel-Timmer CF, van Mourik-Noordenbos A. Bielschowsky head-tilt test. I. Ocular counterrolling and Bielschowsky head-tilt test in 23 cases of superior oblique palsy. Vision Res 1985; 25 : $1977-1982$.

22. Robinson DA. Bielschowsky head-tilt test. II. Quantitative mechanics of the Bielschowsky head-tilt test. Vision Res 1985; 25:1983-1988.

23. Kommerell G, Klein U. Adaptive changes of the otolith-reflex after injury to the trochlea. Neuro-ophthalmology 1986; 6:101-107.

24. Herzau V, Joos E. Untersuchungen von Bewegungen und Stellungsfehlern der Augen um ihre sagittale Achse. Z Prakt Augenheilk 1983; 4:270-278. 